\title{
Effects of caffeine ingestion on dynamic visual acuity: a placebo-controlled, double-blind, balanced-crossover study in low caffeine consumers
}

\author{
Beatríz Redondo ${ }^{1} \cdot$ Raimundo Jiménez $^{1} \cdot$ Rubén Molina $^{1} \cdot$ Kristine Dalton $^{2} \cdot$ Jesús Vera $^{1}$ (I)
}

Received: 1 May 2021 / Accepted: 3 August 2021 / Published online: 22 August 2021

(c) The Author(s) 2021

\begin{abstract}
Background Acute caffeine ingestion has been associated with improvements in cognitive performance and visual functioning. The main objective of this study was to determine the effects of caffeine intake on dynamic visual acuity (DVA). Methods Twenty-one low caffeine consumers (22.5 \pm 1.6 years) took part in this placebo-controlled, double-blind, and balanced crossover study. In two different days and following a random order, participants ingested either caffeine $(4 \mathrm{mg} / \mathrm{kg})$ or placebo, and DVA was measured after $60 \mathrm{~min}$ of ingesting the corresponding capsule. A recently developed and validated software (moV\& test, V\&mp Vision Suite, Waterloo, Canada) was used to assess DVA.

Results We found a greater accuracy for both the horizontal and random motion paths of DVA after caffeine ingestion $(p<0.001$ and $p=0.002$, respectively). In regard to the speed of the response, our data revealed that caffeine intake was associated with a faster reaction time for horizontally $(p=0.012)$ but not for randomly $(p=0.846)$ moving targets. Also, participants reported higher levels of perceived activation after consuming caffeine in comparison to placebo $(p<0.001)$.

Conclusions Our data suggest that caffeine intake (i.e., a capsule containing $4 \mathrm{mg} / \mathrm{kg}$ ) has an ergogenic effect on DVA, which may be of special relevance in real-word contexts that require to accurately and rapidly detect moving targets (e.g., sports, driving, or piloting).
\end{abstract}

Keywords Visual perception $\cdot$ Caffeine $\cdot$ Ergogenic effect $\cdot$ Psychostimulants $\cdot$ Visual function

\section{Introduction}

Dynamic visual acuity (DVA) is defined as the ability to resolve fine details when there is relative motion between the target and the observer (Miller and Ludvigh 1962). Research has demonstrated that DVA plays an important role in multiple real-word situations, mainly in those that involve operating in dynamic environments with moving objects such as different ball sports (Ishigaki and Miyao 1993; Quevedo-Junyent et al. 2011), driving (Hwang et al. 2020), and piloting (Kohl et al. 1991; Peters et al. 2011). DVA is

Raimundo Jiménez

raimundo@ugr.es

1 CLARO (Clinical and Laboratory Applications of Research in Optometry) Research Group, Department of Optics, Faculty of Sciences, University of Granada, Campus de la Fuentenueva 2, 18001 Granada, Spain

2 School of Optometry \& Vision Science, University of Waterloo, Waterloo, Canada considered a complex perceptual ability, which requires an appropriate target detection, peripheral awareness, oculomotor functioning, and information processing (Hoffman 1981). However, cognitive processes such as these are sensitive to different external factors such as diurnal variations (Blatter and Cajochen 2007), level of expertise (Ishigaki and Miyao 1993; Williams and Davids 1998), sleep deprivation (Krause et al. 2017), or psychostimulants (McLellan et al. 2016; Connell et al. 2017), among many other factors.

In regard to psychostimulants, caffeine is the most widely consumed psychoactive ingredient, whose popularity is attributed to its benefits for physiological, psychomotor, and cognitive performance (Glade 2010). In the last years, there has been increasing interest in the positive effects of caffeine on a number of visual skills. For example, Connell et al. (2017) observed that caffeine modulates the function of the oculomotor system, increasing the velocity of rapid eye movements. Recent scientific evidence also indicates that caffeine intake has an effect on different visual skills such as contrast sensitivity (Tsunoda et al. 2019), ocular aberrations 
(Bardak et al. 2016), and accommodation (Redondo et al. 2019). In addition, the ingestion of caffeine has been shown to enhance visual processing, facilitating the detection of visual stimuli and response preparation (Kenemans and Lorist 1995).

Taking into account the multiple benefits associated with caffeine consumption on cognitive performance and visual functioning, it is plausible to expect that caffeine ingestion may influence the ability to detect moving objects (i.e., DVA). Nevertheless, to the best of our knowledge, there are no studies that have assessed this hypothesis. In order to address the limitations found in the scientific literature, the aim of this study was to assess the acute effects of caffeine ingestion on DVA. To do so, DVA was measured with a recently developed and validated test (moV\&; V\&MP Vision Suite) (Hirano et al. 2017) before and after the ingestion of a capsule of $4 \mathrm{mg} / \mathrm{kg}$ of caffeine or placebo on two different days in a randomized order. Complementarily, we obtained the perceived levels of activation in order to check the effectiveness of caffeine/placebo manipulation.

\section{Methods}

\section{Participants and ethical approval}

An a priori power analysis for a three-way repeated measure ANOVA, using the GPower 3.1 software (Faul et al. 2007), was conducted to calculate the minimum sample size. We assumed an effect size of 0.30, alpha of 0.05, and power of 0.80 , and it projected that seventeen participants were required for this study. After completing the power analysis, twenty-one low caffeine consumers (11 women and 10 men; mean age \pm standard deviation $=22.5 \pm 1.6$ years; mean weight \pm standard deviation $=68.4 \pm 9.9 \mathrm{~kg}$ ) took part in this study. All participants met the following inclusion criteria: (i) free of any ocular disease, as assessed by slit lamp and direct ophthalmoscopy examination; (ii) had an uncorrected refractive error lower than $0.50 \mathrm{D}$ of myopia and astigmatism and $1 \mathrm{D}$ of hyperopia; (iii) had a static visual acuity at far distance $\leq 0 \log$ MAR in each eye with their best optical correction; (iv) belonged to the low visual discomfort group with the Conlon survey (Conlon et al. 1999); and (v) had no history of allergy to xantic bases or cardiovascular problems. This study adhered to the tenets of the Declaration of Helsinki and was approved the University of Granada Institutional Review Board (IRB approval: 438/CEIH/2017). All participants signed an informed consent form.

\section{Subjective questionnaires}

In order to ensure that participants attended the laboratory under similar conditions, they reported their subjective levels of arousal before each experimental session (placebo and caffeine). Subjective levels of arousal were assessed using the Stanford Sleepiness Scale (SSS) which consists in a 7-point Likert, ranging from 1 "very active, alert or awake" to 7 "very sleepy" (Hoddes et al. 1973). Also, at the beginning of each experimental session, as well as $60 \mathrm{~min}$ after caffeine/placebo intake, participants were asked to complete a visual analogue scale in order to determine their subjective level of activation ( 0 absolutely not activated and 10 extremely activated), which has been used in similar investigations (Redondo et al. 2019, 2020).

\section{Dynamic visual acuity test}

DVA was measured using the moV\& test (V\&mp Vision Suite, Waterloo, Canada), which has been validated and demonstrated good test-retest repeatability (Hirano et al. 2017). The target used was a single letter "Tumbling E" chart, which was presented in black on a white background at four orientations (right, left, up, or down). Participants, who wore their best optical correction, had to indicate the correct orientation of the branches of the letter $E$ with the arrow keys of the keyboard. The DVA test started with size letters of $0.8 \log$ MAR, and five letters were consecutively presented with each stimulus size. If participants correctly identified at least 3 out of 5 trials, the letter size was reduced in steps of $0.1 \log$ MAR. The test was interrupted when participants did not identify 3 or more targets for a given letter size.

The testing was performed at $4 \mathrm{~m}$ using a 55 -inch TV monitor (Sony 55-XF9005, Tokyo, Japan). We measured DVA for horizontal (target moved across the screen from left to right only once) and random motion paths (target moved following a random Brownian motion) at four target speeds based on the limitations of the ocular pursuit system $(0.34,0.71,1.46$, and $2.31 \mathrm{~m} / \mathrm{s}$, which is equivalent to 5,10 , 20, and 30\%) (Gresty \& Leech, 1977; Yee, 2017). Following a randomized order, each participant performed a total of 8 trials ( 2 motion paths $\times 4$ target speeds). The target was shown for a maximum $20 \mathrm{~s}$ or until participants responded to the orientation of the letter; then, the next trial immediately started. Visual acuity (VA) and reaction time (RT) were analyzed for each trial.

\section{Procedure}

Participants visited the laboratory on three different days, with all experimental sessions being scheduled at the same time $( \pm 1 \mathrm{~h})$ to avoid the influence of circadian variations (Read et al. 2008). In the first session, a complete visual examination was performed by an experienced optometrist to verify that subjects met inclusion criteria, as well as to obtain information about their daily caffeine consumption 
and their anthropometric characteristics. They were also familiarized with the software used for DVA assessment and were allowed to practice for $5 \mathrm{~min}$. The second and third experimental sessions comprised the main experimental part of this study, with both sessions being identical, except for the ingestion of caffeine or placebo. Upon arrival to the laboratory, participants were asked to fill the SSS and report their level of activation and perform the DVA test. After this testing, participants ingested, in counterbalanced order, a capsule of caffeine or placebo along with a cup of water $(100 \mathrm{ml})$. Sixty minutes after caffeine/placebo ingestion, participants reported their level of activation and performed the DVA test.

Each placebo capsule was comprised of $300 \mathrm{mg}$ of corn starch, and the caffeine capsules (caffeine anhydrous) were dispensed in steps of $20 \mathrm{mg}$, being prepared based on participant's weight $(\sim 4 \mathrm{mg} / \mathrm{kg})$. The average weight of the experimental sample was $68.4 \pm 9.9 \mathrm{~kg}$, which resulted in an average caffeine dosage of $273.3 \pm 40.7 \mathrm{mg}$. Both were prepared by a pharmacist laboratory (Acofarma distribución S.A., Madrid, Spain) and packaged identically in an opaque gelatine capsule to avoid identification of contents by shape, taste, or color. Aiming to accomplish the double-blind procedure, the capsules were coded and prepared by a third person.

\section{Statistical analyses}

The normal distribution of the data (Shapiro-Wilk test) and the homogeneity of variances (Levene's test) were confirmed $(p>0.05)$. In order to assess whether participants had similar levels of alertness/sleepiness in both experimental sessions, a paired samples $t$-test, considering the session (session 1, session 2) as the only withinparticipants factor, was performed for the scores reported on the SSS at the beginning of each session. Also, the impact of caffeine consumption on the levels of activation was checked by a two-way repeated measure ANOVA (substance [caffeine, placebo], point of measure [pre, $60 \mathrm{~min}]$ ) that was carried out. For the main analyses, we performed four separate three-way repeated measures ANOVA (substance [caffeine, placebo], point of measure [pre, $60 \mathrm{~min}$ ], and target velocity [velocity 1 , velocity 2 , velocity 3 , velocity 4]) for horizontal RT, random RT, horizontal DVA, and random DVA. Effect sizes were reported by means of Cohen's $d$ and partial eta-squared $\left(\eta_{p}{ }^{2}\right)$ for $t$ and $F$ tests, respectively. The level of statistical significance was set at 0.05 , and the Holm-Bonferroni procedure was applied for multiple comparisons.

\section{Results}

\section{Effectiveness of the experimental manipulation}

Participants reported comparable levels of sleepiness/ alertness at the beginning of both experimental sessions $\left(t_{20}=0.271, p=0.789, d=0.06\right)$. For the level of activation, there were significant differences for the substance $\left(F_{1,20}=40.51, p<0.001, \eta_{p}{ }^{2}=0.67\right)$, point of measure $\left(F_{1,20}=39.17, p<0.001, \eta_{p}{ }^{2}=0.66\right)$, and the interaction substance $\times$ point of measure $\left(F_{1,20}=26.36, p<0.001\right.$, $\left.\eta_{p}{ }^{2}=0.57\right)$. Consequently, we performed two separate paired samples $t$-tests for the subjective scores of activation in both experimental sessions (caffeine, placebo), considering the point of measure as the only within-participants factor. These analyses revealed that participants reported higher levels of activation after caffeine intake $\left(t_{20}=8.22, p<0.001, d=1.79\right)$, but not after ingesting the placebo capsule $\left(t_{20}=0.34, p=0.741, d=0.08\right)$ (Fig. 1).
Fig. 1 Individual comparisons of the subjective scores of activation in the caffeine and placebo conditions before and after 60 min of capsule ingestion (A) and scatterplot of the changes in subjective scores of activation in the caffeine and placebo conditions (B). The horizontal lines in panel $\mathbf{B}$ indicate the average change
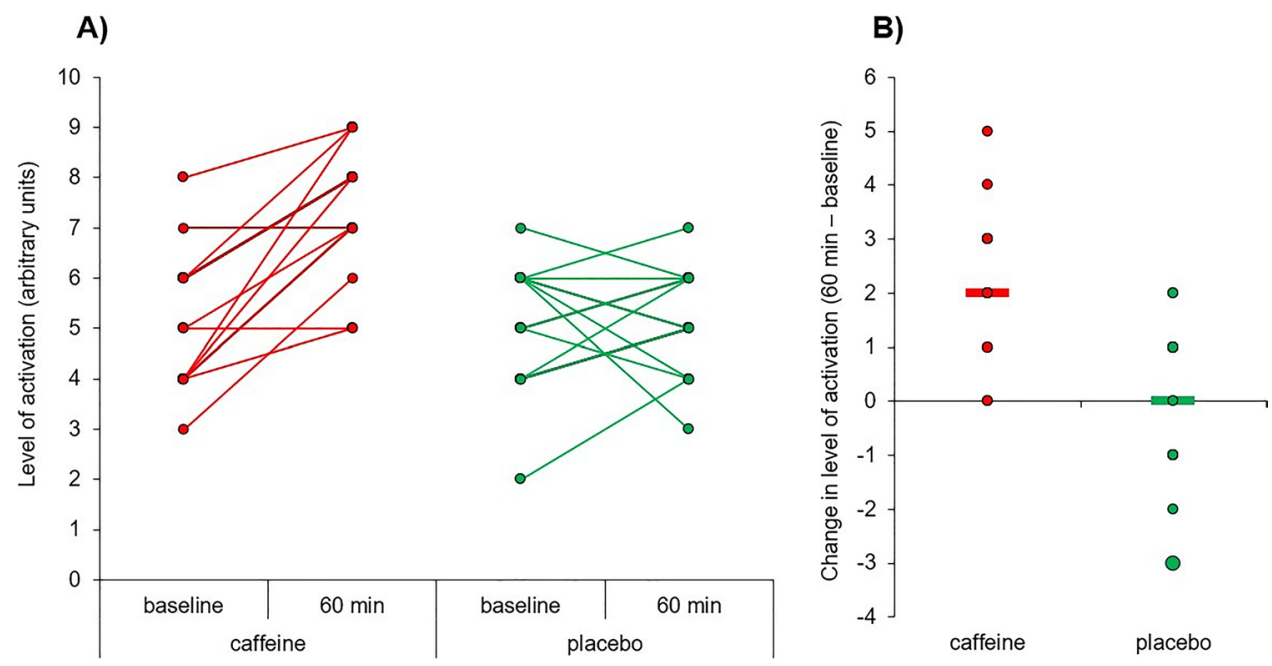


\section{Effects of caffeine intake on DVA}

Table 1 shows descriptive values for the DVA parameters assessed in this study.

For the horizontal RT, we found a statistically significant effect for the target velocity $\left(F_{3,60}=25.28, p<0.001\right.$, $\left.\eta_{p}{ }^{2}=0.56\right)$ and the interaction "substance $\times$ point of measure" $\left(F_{1,20}=4.37, p=0.049, \eta_{p}{ }^{2}=0.18\right)$. No differences were observed for the main effects of substance $\left(F_{1,20}=0.38\right.$, $p=0.546)$ and point of measure $\left(F_{1,20}=1.79, p=0.197\right)$, as well as any other interactive effect (all Ps $>0.544$ ). Complementarily, we performed two separate (2 [point of measure] $\times 4$ [velocity]) ANOVAs for the caffeine and placebo conditions. For the caffeine condition, the horizontal RT was significantly shorter after caffeine intake $\left(F_{1,20}=7.64\right.$, $\left.p=0.012, \eta_{p}{ }^{2}=0.28\right)$, and faster target velocities caused shorter horizontal RTs $\left(F_{3,60}=24.09, p<0.001, \eta_{p}{ }^{2}=0.55\right)$.
The interactive effect "point of measure $\times$ target velocity" did not reach statistical significance $\left(F_{3,60}=1.06, p=0.373\right)$. For the placebo condition, faster target velocities were associated with shorter horizontal RTs $\left(F_{3,60}=9.86, p<0.001\right.$, $\eta_{p}{ }^{2}=0.33$ ), but no effects were observed for the point of measure $\left(F_{1,20}=0.04, p=0.852\right)$ or the interaction "point of measure $\times$ target velocity" $\left(F_{3,60}=0.23, p=0.877\right)($ Fig. $2 \mathrm{~A})$.

The analysis of the random RT yielded a statistically significant effect for the target velocity $\left(F_{3,60}=58.49, p<0.001\right.$, $\left.\eta_{p}{ }^{2}=0.75\right)$, but no differences were obtained for the main effects of substance $\left(F_{1,20}=0.04, p=0.846\right)$ and point of measure $\left(F_{1,20}=0.67, p=0.424\right)$, as well as for any interaction (all Ps $>0.505$ ) (Fig. 2B).

For the horizontal DVA, there were a statistically significant effect of the point of measure $\left(F_{1,20}=16.17\right.$, $\left.p<0.001, \eta_{p}{ }^{2}=0.45\right)$, target velocity $\left(F_{3,60}=117.37\right.$, $\left.p<0.001, \eta_{p}{ }^{2}=0.85\right)$, and the interaction "substance $\times$ point

Table 1 Descriptive values (mean \pm standard deviation) for the dynamic visual acuity parameters assessed at the different measurement moments in both experimental conditions

\begin{tabular}{|c|c|c|c|c|c|c|c|c|c|}
\hline & & \multicolumn{2}{|c|}{ Velocity $1(0.34$ m/s) } & \multicolumn{2}{|c|}{ Velocity $2(0.71 \mathrm{~m} / \mathrm{s})$} & \multicolumn{2}{|c|}{ Velocity $3(1.46 \mathrm{~m} / \mathrm{s})$} & \multicolumn{2}{|c|}{ Velocity $4(2.31 \mathrm{~m} / \mathrm{s})$} \\
\hline & & Pre & $60 \mathrm{~min}$ & Pre & $60 \mathrm{~min}$ & Pre & $60 \mathrm{~min}$ & Pre & $60 \mathrm{~min}$ \\
\hline \multirow[t]{2}{*}{ RT horizontal (ms) } & Caffeine & $890 \pm 130$ & $832 \pm 100$ & $848 \pm 125$ & $820 \pm 92$ & $777 \pm 82$ & $745 \pm 56$ & $733 \pm 114$ & $705 \pm 81$ \\
\hline & Placebo & $878 \pm 159$ & $865 \pm 156$ & $826 \pm 113$ & $835 \pm 142$ & $791 \pm 215$ & $790 \pm 140$ & $734 \pm 128$ & $752 \pm 125$ \\
\hline \multirow[t]{2}{*}{ RT random (ms) } & Caffeine & $835 \pm 111$ & $832 \pm 112$ & $933 \pm 179$ & $916 \pm 189$ & $1040 \pm 254$ & $1018 \pm 221$ & $1117 \pm 271$ & $1057 \pm 216$ \\
\hline & Placebo & $824 \pm 97$ & $817 \pm 113$ & $923 \pm 156$ & $922 \pm 148$ & $1022 \pm 170$ & $1015 \pm 171$ & $1136 \pm 230$ & $1129 \pm 193$ \\
\hline \multirow[t]{2}{*}{ VA horizontal (logMAR) } & Caffeine & $0.07 \pm 0.12$ & $0.05 \pm 0.09$ & $0.19 \pm 0.14$ & $0.11 \pm 0.09$ & $0.33 \pm 0.13$ & $0.25 \pm 0.11$ & $0.42 \pm 0.18$ & $0.31 \pm 0.16$ \\
\hline & Placebo & $0.05 \pm 0.12$ & $0.06 \pm 0.12$ & $0.16 \pm 0.11$ & $0.18 \pm 0.14$ & $0.31 \pm 0.11$ & $0.27 \pm 0.13$ & $0.39 \pm 0.14$ & $0.34 \pm 0.13$ \\
\hline \multirow[t]{2}{*}{ VA random $(\log M A R)$} & Caffeine & $0.15 \pm 0.13$ & $0.11 \pm 0.16$ & $0.26 \pm 0.13$ & $0.18 \pm 0.14$ & $0.39 \pm 0.19$ & $0.33 \pm 0.15$ & $0.51 \pm 0.20$ & $0.43 \pm 0.17$ \\
\hline & Placebo & $0.15 \pm 0.08$ & $0.13 \pm 0.14$ & $0.23 \pm 0.11$ & $0.23 \pm 0.14$ & $0.40 \pm 0.10$ & $0.38 \pm 0.13$ & $0.48 \pm 0.16$ & $0.49 \pm 0.16$ \\
\hline
\end{tabular}

Note: $R T$ reaction time, $V A$ visual acuity, $m s$ milliseconds, logMAR logarithm of minimum angle of resolution, $m / s$ meters per second

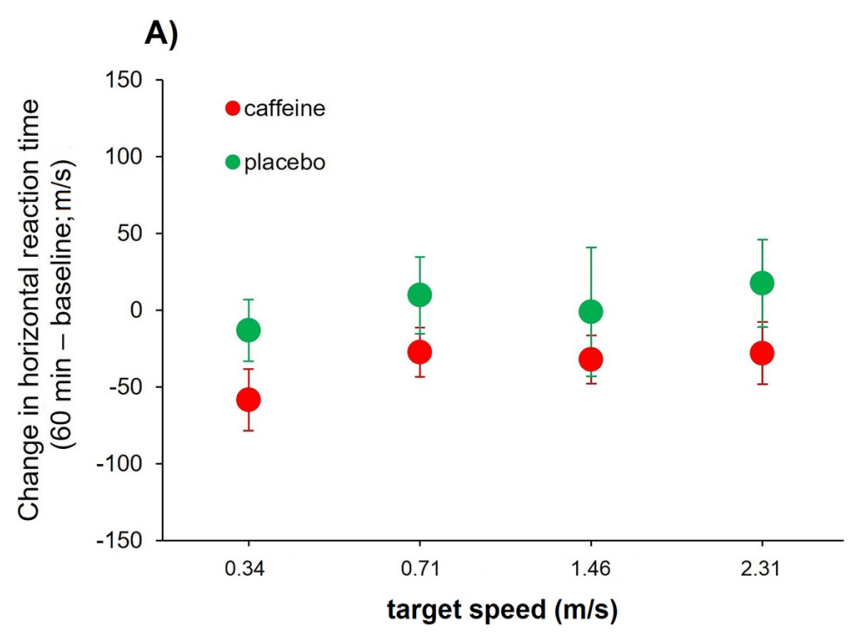

Fig. 2 Mean changes in horizontal (A) and random (B) reaction times in the caffeine (in red) and placebo (in green) conditions at the four velocities in which the visual target was presented. Values are calculated as the difference between the measure taken after $60 \mathrm{~min}$ of

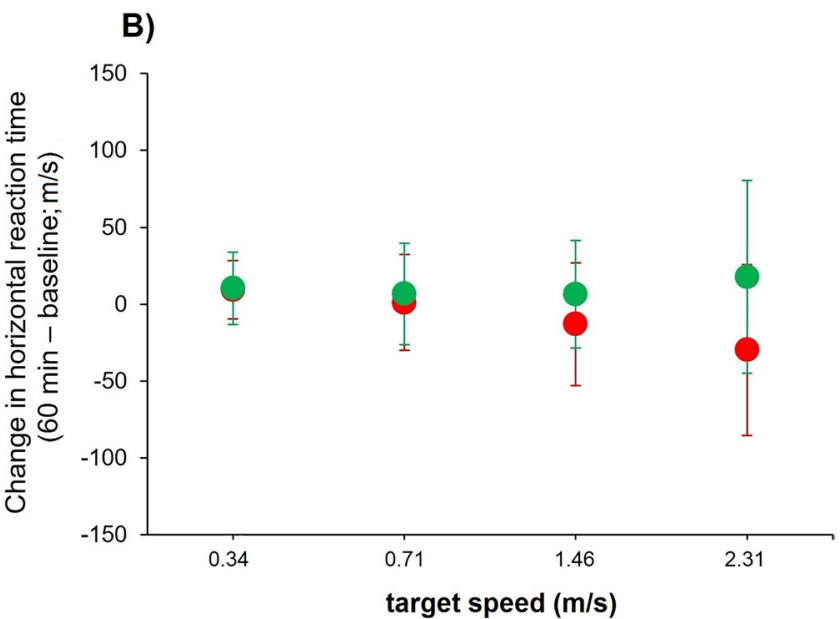

caffeine/placebo intake and the baseline measure taken at baseline. Error bars show the standard error. All values are calculated across participants $(n=21)$. Note: ms, milliseconds; logMAR, logarithm of minimum angle of resolution; $\mathrm{m} / \mathrm{s}$, meters per second; min, minutes 
of measure" $\left(F_{1,20}=6.03, p=0.023, \eta_{p}{ }^{2}=0.23\right)$. Also, the interaction "point of measure $\times$ target velocity" $\left(F_{3,60}=2.70\right.$, $p=0.053, \eta_{p}{ }^{2}=0.12$ ) showed a marginal effect, whereas no statistically significant differences were obtained for main effect of substance $\left(F_{1,20}=0.08, p=0.785\right)$, the interactions "substance $\times$ target velocity" $\left(F_{3,60}=0.21, p=0.889\right)$, and "substance $\times$ point of measure $\times$ target velocity" $\left(F_{3,60}=0.50\right.$, $p=0.685$ ). Thus, we carried out separate (2 [point of measure] $\times 4$ [velocity]) ANOVAs for the caffeine and placebo conditions in order to clarify the differences observed for the interactions in the main analysis. In the caffeine condition, we obtained a statistically significant effect for the point of measure $\left(F_{1,20}=17.16, p<0.001, \eta_{p}{ }^{2}=0.46\right)$ and target velocity $\left(F_{3,60}=77.83, p<0.001, \eta_{p}{ }^{2}=0.80\right)$, showing a better DVA after caffeine intake and with lower velocities of target motion. No differences were observed for the interaction "point of measure $\times$ target velocity" $\left(F_{3,60}=1.78\right.$, $p=0.230)$. For the placebo condition, the main factor of target velocity reached statistical significance $\left(F_{3,60}=67.03\right.$, $p<0.001, \eta_{p}{ }^{2}=0.77$ ), with lower velocities being associated with better VA. However, no effects were obtained for the main effect of point of measure $\left(F_{1,20}=1.38, p=0.255\right)$ or the interaction "point of measure $\times$ target velocity" $\left(F_{3,60}=1.37, p=0.261\right)$ (Fig. 3A).

Lastly, we analyzed the changes in random DVA, observing a statistically significant effect for the point of measure $\left(F_{1,20}=9.05, p=0.007, \eta_{p}{ }^{2}=0.31\right)$, target velocity $\left(F_{3,60}=124.51, p<0.001, \eta_{p}{ }^{2}=0.86\right)$, and the interaction "substance $\times$ point of measure" $\left(F_{1,20}=6.17, p=0.022\right.$, $\left.\eta_{p}{ }^{2}=0.24\right)$. The main effect of substance $\left(F_{1,20}=0.75\right.$, $p=0.398$ ) and the rest of interactions (all Ps > 0.704) did not reach statistical significance. Again, two separate (2 [point of measure] $\times 4$ [velocity]) ANOVAs for the caffeine and placebo conditions were conducted. For the caffeine condition, there were statistically significant differences for the point of measure $\left(F_{1,20}=12.26, p=0.002, \eta_{p}{ }^{2}=0.3\right)$ and target velocity $\left(F_{3,60}=52.91, p<0.001, \eta_{p}{ }^{2}=0.73\right)$, but not for the interaction "point of measure $\times$ target velocity" $\left(F_{3,60}=0.19, p=0.903\right)$. Overall, the ingestion of caffeine lead to better DVA, and faster velocities of target motion were associated with worse DVA. The analysis of the placebo condition exhibited a statistically significant effect of target velocity $\left(F_{3,60}=125.13, p<0.001, \eta_{p}{ }^{2}=0.86\right)$, indicating that faster velocities of target motion caused reduced DVAs. No differences were obtained for the point of measure $\left(F_{1,20}=0.23, p=0.634\right)$ or the interaction "point of measure $\times$ target velocity" $\left(F_{3,60}=0.25, p=0.862\right)$ (Fig. 3B).

\section{Discussion}

Although there is evidence that caffeine improves several visual and cognitive skills, no studies have investigated the acute effects of caffeine on DVA performance. In view of this, we decided to investigate the changes in DVA after caffeine $(\sim 4 \mathrm{mg} / \mathrm{kg})$ or placebo consumption. Our results showed a significant improvement in DVA after caffeine ingestion for both the horizontal and random motion paths. RT was also significatively shorter after caffeine intake for the horizontal motion but not for the random motion condition. As expected, we did not find significant effects for the placebo condition for DVA and RT. Faster velocities of target motion were associated with worse DVA and faster RT in both caffeine and placebo conditions. In addition, greater levels of activation were obtained in the caffeine condition,

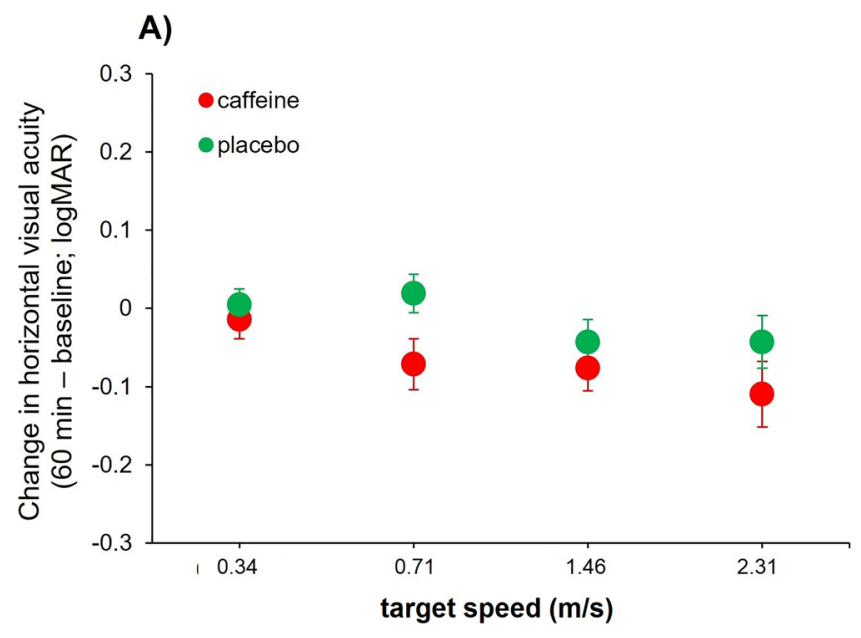

Fig. 3 Mean changes in horizontal (A) and random (B) visual acuities in the caffeine (in red) and placebo (in green) conditions at the four velocities in which the visual target was presented. Values are calculated as the difference between the measure taken after $60 \mathrm{~min}$

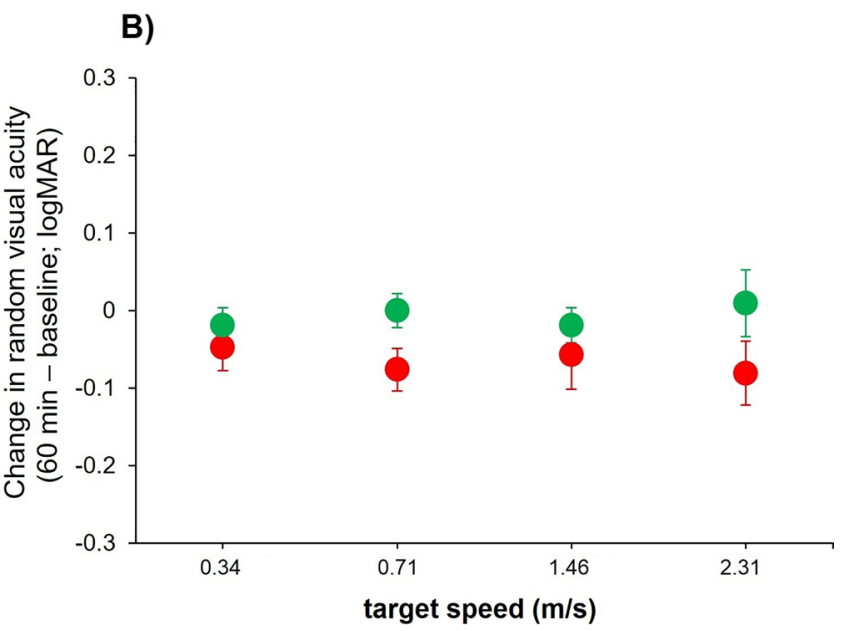

of caffeine/placebo intake and the baseline measure taken at baseline. Error bars show the standard error. All values are calculated across participants $(n=21)$. Note: $\log$ MAR, logarithm of minimum angle of resolution; $\mathrm{m} / \mathrm{s}$, meters per second; min, minutes 
confirming the arousing effect of caffeine shown in the related literature (Glade 2010).

Caffeine is a central nervous system stimulant that acts as an adenosine receptor antagonist (Ferré 2008). There is a considerable amount of research illustrating that caffeine ingestion modifies human behavior (Lorist and Tops 2003; Smith et al. 2003; Glade 2010; Einöther and Giesbrecht 2013; McLellan et al. 2016; Connell et al. 2017; Pomportes et al. 2017). In this regard, our results showed that caffeine consumption increased subjective levels of activation, which agrees with many studies that proved that caffeine enhances alertness and feelings of wakefulness and energy (Zwyghuizen-Doorenbos et al. 1990; Smith 2002; Lorist and Tops 2003).

The ingestion of caffeine improves cognitive and psychomotor performance. For example, studies examining the acute effects of caffeine on RT have found that caffeine consumption improves the accuracy and speed responses of simple RT (Clubley et al. 1979; Jacobson and Edgley 1987; Smith et al. 1994) and choice RT (Mackay et al. 2002; Smith et al. 2003; Smith 2009; Giles et al. 2012). In the same line, we observed that caffeine reduced the time used to detect the moving objects in the DVA test. The faster RTs observed under the effects of caffeine could be explained by the positive influence of caffeine on stimulus processing and decision-making (Saville et al. 2018). However, we just observed this effect (faster RT after caffeine intake) for horizontally moving targets, but not with the random motion path, which could be due to the shorter presentation time of the horizontal targets.

Previous studies have found that DVA is dependent on target velocity, showing a negative association with target velocity (Demer and Amjadi 1993; Long and Vogel 1998). Here, we also found that DVA was worse with faster target speeds in both the caffeine and placebo conditions. Interestingly, our results showed that participants correctly identified smaller moving stimuli after caffeine ingestion compared to ingestion of the placebo. This finding was observed for both horizontally and randomly moving targets, which suggests that caffeine ingestion improved DVA. To the best of our knowledge, there are no studies that have assessed the impact of caffeine on visual acuity, in either static or dynamic conditions. However, it should be noted that while good static visual acuity is a necessary for a good DVA, the correlation between static and DVA is low (Fergenson and Suzansky 1973) because DVA is thought to be a more complex visual function task that involves additional perceptual processes (Quevedo-Junyent et al. 2011). Eye movements and contrast sensitivity, which are implicated in DVA performance, are sensitive to caffeine. Specifically, caffeine increases peak saccade velocity (Connell et al. 2017) and improves perceptual contrast sensitivity (Nguyen et al. 2018; Tsunoda et al. 2019). In addition, visual processing is more effective under caffeine effects, since it allows to improve the ability to analyze spatial frequencies orientation (Kenemans and Lorist 1995) and increase selectivity of relevant information (Lorist et al. 1996). Therefore, the effects of caffeine on DVA could result from improving any, or all, of these attributes required for an accurate DVA. However, our results cannot confirm which mechanisms explain the current findings, and further studies are required to ascertain the underlying mechanisms responsible of the benefits of caffeine intake on DVA.

DVA is considered a visual ability with high ecological validity and determines our performance in several tasks and activities of daily life (National Research Council (US) Committee on Vision 1985). In this study, we observed that caffeine ingestion improves DVA performance. Therefore, the ingestion of caffeine could be recommended in tasks that have demanding attentional requirements and/or tasks that require good resolution of moving targets such as driving or dynamic sports. The current results may be of interest in research and applied settings; however, this study presents some limitations that should be acknowledged. First, the behavioral response to caffeine depends on habitual caffeine intake (Attwood et al. 2007; Einöther and Giesbrecht 2013). Here, participants were low caffeine consumers (less than 2 cups of coffee per day), and it is plausible that the effect of caffeine intake on DVA was likely more pronounced in this experimental sample. It would be interesting to study high caffeine consumers to determine if the effect of caffeine on DVA performance is subject to tolerance. Second, DVA is related to external factors such as age, stimuli contrast, and exposure time, among others (Brown 1972; Reading 1972; Ishigaki and Miyao 1994; Altinkaynak et al. 2016). In this study, these factors were kept constant, and we did not consider how they could mediate the DVA changes caused by caffeine intake. Third, we carried out a thoughtful doubleblind procedure in order to ensure that participants were unaware of the substance type ingested. However, we did not ask them to report which capsule they thought they received in each session, and it would have supported the effectiveness of the double-blind procedure. Fourth, there are considerable inter-individual differences in the physiological and behavioral responsiveness to caffeine (Nehlig 2018), and also, the impact of caffeine on humans has been shown to be dependent on the dose ingested (Quinlan et al. 2000; Chen and Parrish 2009) and the time elapsed after caffeine consumption (Magkos and Kavouras 2005). It should be noted that participants of this study ingested an average caffeine dose of $273.3 \pm 40.7 \mathrm{mg}$, which is equivalent to approximately two espressos based on the findings of Crozier et al. (2012) who obtained a median value of $140 \mathrm{mg}$ of caffeine in servings of espresso coffee. Lastly, we used a specific psychostimulant (i.e., caffeine), and the impact of other substances on DVA has not investigated. Therefore, 
our findings should be cautiously interpreted in this regard, and future studies should consider assessing the mediating role of the aforementioned factors on DVA performance.

\section{Conclusions}

This placebo-controlled, double-blind, balanced crossover study demonstrated that acute caffeine ingestion $(4 \mathrm{mg} / \mathrm{kg})$ improves dynamic visual acuity and reduces RT in comparison to placebo consumption. The positive changes of caffeine on visual and cognitive skills are proposed as a potential explanation of these findings. The acute improvements of DVA with caffeine could have positive implications in real-life activities that require a good DVA for moving targets (e.g., sports, driving, or piloting).

Acknowledgements The authors thank all the participants who selflessly collaborated in this research.

Funding Funding Open Access funding provided thanks to the CRUECSIC agreement with Springer Nature. Funding for open access charge: Universidad de Granada / CBUA.

\section{Declarations}

Conflict of interest The authors declare no competing interests.

Open Access This article is licensed under a Creative Commons Attribution 4.0 International License, which permits use, sharing, adaptation, distribution and reproduction in any medium or format, as long as you give appropriate credit to the original author(s) and the source, provide a link to the Creative Commons licence, and indicate if changes were made. The images or other third party material in this article are included in the article's Creative Commons licence, unless indicated otherwise in a credit line to the material. If material is not included in the article's Creative Commons licence and your intended use is not permitted by statutory regulation or exceeds the permitted use, you will need to obtain permission directly from the copyright holder. To view a copy of this licence, visit http://creativecommons.org/licenses/by/4.0/.

\section{References}

Altinkaynak H, Ceylan E, Kartal B et al (2016) Measurement of choroidal thickness following caffeine intake in healthy subjects. Curr Eye Res 41:708-714. https://doi.org/10.3109/02713683. 2015.1020168

Attwood AS, Higgs S, Terry P (2007) Differential responsiveness to caffeine and perceived effects of caffeine in moderate and high regular caffeine consumers. Psychopharmacology 190:469-477. https://doi.org/10.1007/s00213-006-0643-5

Bardak H, Gunay M, Mumcu U, Bardak Y (2016) Effect of single administration of coffee on pupil size and ocular wavefront aberration measurements in healthy subjects. Biomed Res Int 9578308https://doi.org/10.1155/2016/9578308

Blatter K, Cajochen C (2007) Circadian rhythms in cognitive performance: methodological constraints, protocols, theoretical underpinnings. Physiol Behav 90:196-208. https://doi.org/10. 1016/j.physbeh.2006.09.009

Brown B (1972) The effect of target contrast variation on dynamic visual acuity and eye movements. Vision Res 12:1213-1224

Chen Y, Parrish TB (2009) Caffeine dose effect on activation-induced BOLD and CBF responses. Neuroimage 46:577-583. https://doi. org/10.1016/j.neuroimage.2009.03.012

Clubley M, Bye C, Henson T et al (1979) Effects of caffeine alone and in combination on human performance, subjective effects and EEG activity. Br J Clin Pharmacol 7:157-163

Conlon EG, Lovegrove WJ, Chekaluk E, Pattison PE (1999) Measuring Visual Discomfort vis Cogn 6:637-663. https://doi.org/10.1080/ 135062899394885

Connell CJW, Thompson B, Turuwhenua J et al (2017) Caffeine increases the velocity of rapid eye movements in unfatigued humans. Psychopharmacology 234:2311-2323. https://doi.org/ 10.1007/s00213-017-4638-1

Crozier TWM, Stalmach A, Lean MEJ, Crozier A (2012) Espresso coffees, caffeine and chlorogenic acid intake: potential health implications. Food Funct 3:30-33. https://doi.org/10.1039/c1fo10240k

Demer J, Amjadi F (1993) Dynamic visual acuity of normal subjects during vertical optotype and head motion. Investig Ophthalmol vis Sci 34:1894-1906

Einöther SJL, Giesbrecht T (2013) Caffeine as an attention enhancer: reviewing existing assumptions. Psychopharmacology 225:251274. https://doi.org/10.1007/s00213-012-2917-4

Faul F, Erdfelder E, Lang A-G, Buchner A (2007) G*Power 3: a flexible statistical power analysis program for the social, behavioral, and biomedical sciences. Behav Res Methods 39:175-191. https:// doi.org/10.3758/BF03193146

Fergenson P, Suzansky J (1973) An investigation of dynamic and static visual acuity. Perception 2:343-356. https://doi.org/10.1068/ p020343

Ferré S (2008) An update on the mechanisms of the psychostimulant effects of caffeine. J Neurochem 105:1067-1079. https://doi.org/ 10.1111/j.1471-4159.2007.05196.x

Giles G, Mahoney C, Brunyé T et al (2012) Differential cognitive effects of energy drink ingredients: caffeine, taurine, and glucose. Pharmacol Biochem Behav 102:569-577

Glade MJ (2010) Caffeine-not just a stimulant. Nutrition 26:932-938. https://doi.org/10.1016/j.nut.2010.08.004

Gresty M, Leech J (1977) Coordination of the head and eyes in pursuit of predictable and random target motion. Aviat Space, Environ Med 48:741-744

Hirano M, Hutchings N, Simpson T, Dalton K (2017) Validity and repeatability of a novel dynamic visual acuity system. Optom vis Sci 94:616-625. https://doi.org/10.1097/OPX.0000000000001065

Hoddes E, Zarcone V, Dement W (1973) Quantification of sleepiness: a new approach. Psychophysiology 10:431-436

Hoffman LG (1981) Dynamic visual acuity: a review. J Am Optom Assoc 52:883-886

Hwang S, Kim S, Lee D (2020) Driving performance evaluation correlated to age and visual acuities based on VR technologies. J AdvTransp 2020https://doi.org/10.1155/2020/5898762

Ishigaki H, Miyao M (1994) Implications for dynamic visual acuity with changes in age and sex. Percept Mot Skills 78:363-369. https://doi.org/10.2466/pms.1994.78.2.363

Ishigaki H, Miyao M (1993) Differences in dynamic visual acuity between athletes and nonathletes. Perceptual Mot Ski 77:35-839

Jacobson B, Edgley B (1987) Effects of caffeine on simple reaction time and movement time. Aviat Space Environ Med 58:1153-1156

Kenemans JL, Lorist MM (1995) Caffeine and selective visual processing. Pharmacol Biochem Behav 52:461-471. https://doi.org/10. 1016/0091-3057(95)00159-T 
Kohl P, Coffey B, Reichow A et al (1991) A comparative study of visual performance in jet fighter pilots and non-pilots. J Behav Optom 5:123-126

Krause AJ, Ben SE, Mander BA et al (2017) The sleep-deprived human brain. Nat Rev Neurosci 18:404-418. https://doi.org/10.1038/nrn. 2017.55

Long G, Vogel C (1998) Predicting the "where" and resolving the "what" of a moving target: a dichotomy of abilities. Perception 27:379-391. https://doi.org/10.1068/p270379

Lorist M, Snel J, Kok A, Mulder G (1996) Acute effects of caffeine on selective attention and visual search processes. Psychophysiology 33:354-361

Lorist MM, Tops M (2003) Caffeine, fatigue, and cognition. Brain Cogn 53:82-94. https://doi.org/10.1016/S0278-2626(03)00206-9

Mackay M, Tiplady B, Scholey A (2002) Interactions between alcohol and caffeine in relation to psychomotor speed and accuracy. Hum Psychopharmacol Clin Exp 17:151-156

Magkos F, Kavouras SA (2005) Caffeine use in sports, pharmacokinetics in man, and cellular mechanisms of action. Crit Rev Food Sci Nutr 45:535-562. https://doi.org/10.1080/1040-830491379245

McLellan TM, Caldwell JA, Lieberman HR (2016) A review of caffeine's effects on cognitive, physical and occupational performance. Neurosci Biobehav Rev 71:294-312. https://doi.org/10. 1016/j.neubiorev.2016.09.001

Miller J, Ludvigh E (1962) The effect of relative motion on visual acuity. Surv Ophthalmol 7:83-116

National Research Council (US) Committee on Vision (1985) Emergent techniques for assessment of visual performance. National Academies Press, Washington, DC

Nehlig A (2018) Interindividual differences in caffeine metabolism and factors driving caffeine consumption. Pharmacol Rev 70:384-411. https://doi.org/10.1124/pr.117.014407

Nguyen B, Hew S, Ly J et al (2018) Acute caffeine ingestion affects surround suppression of perceived contrast. J Psychopharmacol 32:81-88

Peters B, Miller C, Brady R et al (2011) Dynamic visual acuity during walking after long-duration spaceflight. Aviat Space Environ Med 82:463-466

Pomportes L, Brisswalter J, Casini L, et al (2017) Cognitive performance enhancement induced by caffeine, carbohydrate and guarana mouth rinsing during submaximal exercise. Nutrients 9https:// doi.org/10.3390/nu9060589

Quevedo-Junyent L, Aznar-Casanova JA, Merindano-Encina D et al (2011) Comparison of dynamic visual acuity between water polo players and sedentary students. Res Q Exerc Sport 82:37-41. https://doi.org/10.5641/027013611X13275192111664

Quinlan PT, Lane J, Moore KL et al (2000) The acute physiological and mood effects of tea and coffee. Pharmacol Biochem Behav 66:19-28. https://doi.org/10.1016/S0091-3057(00)00192-1
Read SA, Collins MJ, Iskander DR (2008) Diurnal variation of axial length, intraocular pressure, and anterior eye biometrics. Investig Ophthalmol vis Sci 49:2911-2918. https://doi.org/10.1167/iovs. $08-1833$

Reading VM (1972) Visual resolution as measured by dynamic and static tests. Pflügers Arch 333:17-26

Redondo B, Vera J, Carreño-Rodríguez C et al (2020) Acute effects of caffeine on dynamic accommodative response and pupil size: a placebo-controlled, double-blind, balanced crossover study. Curr Eye Res 45:1074-1081. https://doi.org/10.1080/02713683.2020. 1725060

Redondo B, Vera J, Molina R, et al (2019) Caffeine alters the dynamics of ocular accommodation depending on the habitual caffeine intake. Exp Eye Res 185https://doi.org/10.1016/j.exer.2019.05. 003

Saville CWN, de Morree HM, Dundon NM et al (2018) Effects of caffeine on reaction time are mediated by attentional rather than motor processes. Psychopharmacology 235:749-759. https://doi. org/10.1007/s00213-017-4790-7

Smith A (2009) Effects of caffeine in chewing gum on mood and attention. Hum Psychopharmacol Clin Exp 24:239-247

Smith A (2002) Effects of caffeine on human behavior. Food Chem Toxicol 40:1243-1255

Smith A, Brice C, Nash J et al (2003) Caffeine and central noradrenaline: effects on mood, cognitive performance, eye movements and cardiovascular function. J Psychopharmacol 17:283-292. https:// doi.org/10.1177/02698811030173010

Smith A, Kendrick A, Maben A, J S, (1994) Effects of breakfast and caffeine on cognitive performance, mood and cardiovascular functioning. Appetite 22:39-55

Tsunoda K, Sato A, Kurata R et al (2019) Caffeine improves contrast sensitivity of freely moving rats. Physiol Behav 199:111-117

Williams A, Davids K (1998) Visual search strategy, selective attention, and expertise in soccer. Res Q Exerc Sport Exerc Sport 69:111-128

Yee A (2017) Investigation of vision strategies used in a dynamic visual acuity task. 1-61

Zwyghuizen-Doorenbos A, Roehrs TA, Lipschutz L et al (1990) Effects of Caffeine on Alertness. Psychopharmacology (berl) 100:36-39

Publisher's note Springer Nature remains neutral with regard to jurisdictional claims in published maps and institutional affiliations. 